\title{
Controlled Digital Lending... On the Quick and Cheap
}

Drew Baker, Digital Theological Library James Darlack, Vanguard University of Southern California Thomas E. Phillips, Digital Theological Library

\begin{abstract}
In Summer 2020, the Digital Theological Library implemented a Controlled Digital Lending program in order to make print theological resources available online. This "Listen-and-Learn Session" reviewed the background of this initiative, the different systems used for implementation, and the end-user's experience of using the Controlled Digital Lending collection.
\end{abstract}

\section{BACKGROUND (JAMES M. DARLACK)}

In the Summer of 2020, academic libraries were still coping with the complexities of serving students and faculty during a global pandemic. Shutdowns forced many schools to investigate creative solutions to provide crucial content to patrons. Brandon Board and Karl Stutzman (2020a, 2020b) of Anabaptist Mennonite Biblical Seminary (AMBS) presented one such solution at the Atla 2020 Annual Online: "Controlled Digital Lending: An E-book Solution When There Is No E-book?" In their presentation, they demonstrated their use of the Internet Archive to provide a "Controlled Digital Lending" collection. AMBS sent books to the Internet Archive, and the Internet Archive then digitized the books, stored the hard copies, and made the scans available through its digital interface. The AMBS endeavor in Controlled Digital Lending (CDL) sparked the curiosity of librarians associated with the Digital Theological Library (DTL; https:// www.digitaltheologicallibrary.org), who sought to implement a CDL program of their own.

Controlled Digital Lending allows a library to share digitized versions of print materials in place of physically loaning the items to patrons. For this practice to comply with copyright law, it is important to control how many individuals have simultaneous access to the digital copy, how long they can use it, and whether they are 
able to copy and distribute the digital item. The Position Paper on Controlled Digital Lending (https://controlledigitallending.org/statement) proposes that for a CDL program to be successfully implemented, a library needs to:

1) ensure that original works are acquired lawfully;

2) apply CDL only to works that are owned and not licensed;

3) limit the total number of copies in any format in circulation at any time to the number of physical copies the library lawfully owns (maintain an "owned-to-loaned" ratio);

4) lend each digital version only to a single user at a time just as a physical copy would be loaned;

5) limit the time period for each loan to one that is analogous to physical lending; and

6) use digital rights management to prevent wholesale copying and redistribution.

Thus, for DTL to implement a CDL program, the requirements above needed to be fulfilled.

With the Fall 2020 semester quickly approaching, DTL was interested in implementing a CDL solution quickly. The AMBS presentation (Board and Stutzman 2020,158-9) noted multiple limitations of using the Internet Archive to implement CDL in an academic setting, so DTL pursued other avenues. Unfortunately, after a review of various systems that offer Digital Rights Management (DRM) we were not able to find any one service that fulfilled the necessary requirements while offering a long-term inexpensive solution.

It was our desire to implement a system quickly, even though it might need refinement. We also wanted a system that could handle a large volume of digitized texts, as DTL had begun acquiring print volumes from library closures. Of course, expense was certainly an issue - including the hidden cost of open-source solutions. Given these parameters, we decided to improvise by upgrading and pulling together services that DTL was already using, while obtaining digitization equipment that could handle a high volume of scans.

\section{IMPLEMENTATION (THOMAS E. PHILLIPS)}

We made the early decision that we were not going to use any of the books digitized for CDL as a circulating collection, so we did not need 
to coordinate physical loans with digital access. We were also free to guillotine books for faster processing through scanners equipped with an automatic document feeder. To maintain the "owned-toloaned" ratio for digital access, a minimum of three copies of each CDL title were obtained (though only one copy is guillotined for the digitization process). These physical copies are then placed in storage.

For management and discovery of CDL titles, we used our existing subscription to OCLC's WorldShare Management Services and their Collection Manager to create a collection of links to CDL books that is seamlessly integrated into OCLC's WorldShare Discovery. The links listed in Collection Manager would point to LibGuide pages that listed works by a particular author or works in a particular series or set. We upgraded DTL's LibGuides subscription to LibGuides CMS, so that these pages could be IP-authenticated through EZProxy. The LibGuide pages would then hold links to the digitized books that were stored on Dropbox along with passwords that gave access to the documents. We upgraded to Dropbox for Teams in order to increase storage capacity and to facilitate collaboration between staff responsible for digitization and staff responsible for metadata. In Dropbox we disabled the ability for the end user to download, save, or copy and paste material from the scans. This combination of technology (along with the high-volume scanners and book cutters) cost approximately $\$ 5,000$ in start-up capital. Within our first eight months, we digitized over 12,000 titles. Since the start of the CDL program, we have learned that our investment in scanners, parts, and paper cutters is ongoing; for instance, we recently acquired an electric cutter to guillotine books for about $\$ 1,800$.

\section{USER EXPERIENCE (DREW BAKER)}

Our goal was for the CDL collection to seamlessly integrate with our existing catalog of digital materials. Users discover CDL titles indistinguishably intermixed with our other holdings in WorldCat Discovery. (Other DTL libraries that use WorldCat Discovery can also integrate the CDL collection through OCLC's Collection Manager.) Upon selecting a CDL title and authenticating through EZProxy, users are brought to an IP-gated LibGuides page with a link to the title and a note about the password needed for access to the Dropbox file. Upon selecting the link and entering that password, users are brought to a non-downloadable, non-printable PDF. LibGuides and 
Dropbox provide several layers of security in order to create a fully controlled environment for the digitized titles, while the full setup provides an easy-to-use and seamless discovery platform for our CDL collections.

\section{BIBLIOGRAPHY}

Board, Brandon, and Karl Stutzman. 2020a. "Controlled Digital Lending: An E-book Solution When There Is No E-book?” Presented at Atla Annual, June 19. https://vimeo.com/439074597.

_. 2020b. "Controlled Digital Lending: An E-book Solution When There Is No E-book?” Atla Summary of Proceedings 74: 157-65. https://www.doi.org/10.31046/proceedings.2020.1857.

Burger, John, James B. Harper, Lisa A. Macklin, Robin N. Sinn, Tucker Taylor, and Robyn Weisman. 2021. Future Thinking: ASERL's Resource Guide to Controlled Digital Lending for Research Libraries. Atlanta: ASERL. http://www.aserl.org/wp-content/ uploads/2021/03/Future_Thinking_ASERL_Resource_Guide March-2021.pdf.

“CDL Implementers.” 2021. Accessed June 17. https://sites.google. com/view/cdl-implementers.

Hansen, David R., and Kyle K. Courtney. 2018. "A White Paper on Controlled Digital Lending of Library Books.” Preprint. LawArXiv. https://www.doi.org/10.31228/osf.io/7fdyr.

IFLA. 2021. "IFLA Statement on Controlled Digital Lending." The Hague: International Federation of Library Associations and Institutions. https://www.ifla.org/publications/node/93954. 